\title{
MUERTES APARENTES Y SOCORROS ADMINISTRADOS A LOS AHOGADOS Y ASFIXIADOS EN LAS POSTRIMERIAS DEL SIGLO XVIII
}

\author{
Paula de Demerson \\ Doctora e Historiadora
}

\section{RESUMEN}

Desde la Edad Media, el temor de ser enterrado vivo obsesionó la conciencia de muchos países europeos. El siglo XVIII, de espíritu humanista y filantrópico, conmovido por tan desgraciada suerte, se enfrentó con aquel problema de extrema gravedad. A ejemplo de Holanda, nació por toda Europa un gran movimiento de solidaridad a favor de los ahogados y asfixiados, se desplegaron ingentes esfuerzos para volverlos a la vida, y con indudable éxito, pues se salvó así una infinidad de personas.

PALABRAS CLAVE: medicina, Europa, siglo XVIII.

\section{SUMMARY}

Since de Middle Ages, the fear of being burried alive besets the conscience of many countries in Europe. From its humanistic and philantropical perspective, the XVIII century, yearned by such a misfortune, faced this extremely difficult problem. Initiated in The Netherlands, a large movement of solidarity towards the victims of accidents such as drowned or suffocated people, spread all over Europe. Desperate efforts were made to uphold the victims alive that contributed to successfully rescue a huge number of human beings.

KEY WORDS: medicine, Europe, $18^{\text {th }}$ century.

Antiguamente y todavía en el siglo XVIII no muy lejano, no se diferenciaba la muerte verdadera del coma profundo o de los estados letárgicos provocados por una multiplicidad de causas generalmente accidentales (síncope, desmayo, apoplejía, afectos soporosos, alferecía, catalepsia, insulto convulsivo o histérico, éxtasis morboso, vehemente pasión de ánimo como pavor, fuerte ira, pesadumbre o excesiva delectación venérea). $\mathrm{Si}$, como en varios países y en España entre ellos, se practicaba la inhumación en un plazo breve, existía e1 peligro de ser enterrado vivo. Y efectivamente, ocurría con bastante frecuencia aquella horrible desgracia. Unos de estos «muertos vivos» golpeaban con desesperación las paredes del ataúd antes de sucum- 
bir por falta de aire. Otros tenían a veces la suerte inaudita de que alguien oyese sus gritos y su vuelta a la vida se consideraba como auténtico milagro. El temor de ser enterrados vivos era tan fuerte que en Inglaterra ciertas personas exigían llevar atado al dedo un cascabel o una campanita para eventualmente manifestarse desde su féretro. En Alemania, era costumbre destapar en el cementerio el ataúd antes de proceder a la sepultura.

Resultaría imposible hacer el recuento de aquellos desgraciados condenados a la podredumbre que lograron in extremis salvar su vida, o que durante la autopsia que se les hizo, reaccionaron al primer corte de bisturí. Sólo recordaré unos pocos casos históricos. El de D. Diego de Espinosa, cardenal y obispo de Sigüenza, Presidente del Consejo de Castilla en tiempos de Felipe II, víctima de un «parasismo» que le dejó como muerto. Se preparaban a embalsamarlo cuando opuso la mano a la navaja del cirujano. Se supo luego que le había reñido el Rey y de pesadumbre había caído en aquel estado. O también el del Papa Inocencio VIII que, dos años antes de su muerte, fue acometido de tan vehemente síncope que se quedó 22 horas enteramente inmóvil, sin pulso ni respiración, de manera que empezaba ya el Sacro Colegio de Cardenales a tratar de la elección de un nuevo Pontífice, cuando despertó naturalmente. En 1766, la Señora de Scott yacente en su ataúd y a punto de ser enterrada el mismo día de su supuesta muerte, despertó de su letargo al sentir que unos ladrones querían arrancarle su sortija de esmeralda. Recobró todos sus sentidos y cinco años después, dio a luz al célebre novelista Walter Scott. Winslow refiere un caso de catalepsis perfecto sufrido por un religioso franciscano que sacaron de su tumba tres o cuatro días después de enterrado y que se encontró todavía vivo, aunque con las manos roídas.

La falibilidad de las señales vulgares para distinguir la verdadera muerte de la muerte aparente es un tema recurrente que inquieta las conciencias de los países europeos, un problema de extrema gravedad para muchos médicos, ya que su acción obedece a dos reglas intangibles: «siempre es prohibido por las leyes de la humanidad y por el precepto de la religión adelantar la muerte al prójimo de un solo instante».

Desde mediados del siglo XVIII, numerosos tratados surgidos en todo el ámbito de Europa expresan esta preocupación mayor. En Francia, Bruhier d'Ablancourt ${ }^{1}$ publica en 1749 una Disertación sobre la incertidumbre de los signos de la muerte y el abuso de los enterramientos precipitados ${ }^{2}$, traducción de la obra en latín del mismo título de Winslow ${ }^{3}$ dada a luz en París en 1742 y 1745. Para refutar aquel escrito

1 Nacido en Beauvais y fallecido en París en 1756.

2 vols. en $12^{\circ}$.

3 El anatomista dinamarqués Jacob Benignus Winslow nació en Odensée en 1669 y se estableció en Francia en 1698. Le convirtió Bossuet al catolicismo. Fue profesor de anatomía en el Jardín Real, socio de la Academia de las Ciencias y regente de la Facultad de Medicina de París. Falleció en 1760. 
que había levantado grandes temores, Antoine Louis a su vez ${ }^{4}$ redacta Seis cartas sobre la certidumbre de los signos de la muerte llenas de asertos interesantes destinados a tranquilizar a los ciudadanos ${ }^{5}$ y las publica en París en 1752. En Versalles, el 26 de septiembre de 1772 , el maestro cirujano Janin ${ }^{6}$ presenta al Rey y a los infantes la obra que ha compuesto bajo el título de Reflexiones sobre la triste suerte de las personas que bajo una apariencia de muerte fueron enterradas vivas y sobre los medios que conviene poner en uso para prevenir semejante error ${ }^{7}$.

Reveladora de aquella cuestión de palpitante actualidad que concierne a toda Europa, aparece en España en 1775 una Instrucción sobre lo arriesgado que es, en ciertos casos, enterrar a las personas sin constar su muerte por otras señales más que las vulgares y sobre los medios más convenientes para que vuelvan en sí ${ }^{8}$. Es un tratado de clara intención didáctica, de más de quinientas páginas, completísimo, del Doctor D. Miguel Barnades, médico de Cámara de S.M. y Primer Profesor de Botánica en e1 Real Jardín de Plantas de 1a Corte, fallecido tres años antes. Lo da a luz pública su hijo del mismo nombre, simple médico entonces, luego en 1779 socio de la Real Academia de Medicina Matritense. Esta obra póstuma, por su pasmosa erudición y su densidad es fruto de muchas observaciones (ciertas se remontan al año 1743), de grandes investigaciones y reflexiones de largo tiempo atrás, de lecturas de un sinfín de publicaciones antiguas o contemporáneas ${ }^{9}$, lo que significa claramente que su autor se preocupó del grave asunto de las muertes aparentes entre los primeros en Europa. Se divide en dos partes muy pormenorizadas. En la primera, Barnades estudia los funerales en uso en distintas naciones de la antigüedad y la poca o mucha precaución que se tomaba para asegurarse de estar muertos los que iban a sepultarse. Insiste sobre los falsos indicios de muerte que son las señales vulgares (falta de pul-

4 Antoine Louis (1723-1792), nacido en Metz, era hijo de un cirujano mayor del hospital militar de Metz. Fue protegido por La Peyronnie quien adivinó en él sus excelentes dotes, y a la muerte de éste, por La Martinière. En 1746, fue nombrado Académico de las Ciencias. Dejó varias obras de estimación y redactó la sección « Cirujía « de la Enciclopedia.

5 Pequeño en $12^{\circ}$ de 376 págs.

6 Janin de Combe Blanche (1731- 1811), célebre oculista de León de Francia, nació en Carcasona. Fue socio de varias Academias y del Colegio Real de Cirujía de París.

7 La Haya, París (Didot hijo), 1 vol. en $8^{\circ}, 96$ págs.

8 Madrid, Antonio Sancha, Aduana Vieja, 4, 8 h., 510 págs. El anuncio de la obra salió en la Gaceta de Madrid de 5 de marzo de 1776.

9 Miguel Barnades cuya patria, se complace en recordarlo, es Cerdeña, maneja el latín y el francés con soltura Ha profundizado los escritos de los médicos más afamados (Boerhaave, Haller, Sydenham, Gorter, Heister, Hoffmann, Vanswieten, Winwlow, Bruhier, Harveo, Duverney, Piquer, Sauvage, Deventer...). Conoce los historiadores y filósofos griegos y latinos, las Memorias de la Real Academia de Suecia, las Transacciones Filosóficas, el Teatro crítico de Feijo, las Efemérides de la Academia de los $\mathrm{Cu}$ riosos de la Naturaleza, El Diccionario Enciclopédico, las Memorias de la Academia Real de las Ciencias de París etc..etc... Todo esto supone una enorme compilación muy bien ordenada y un trabajo muy concienzudo y riguroso, llevado por un espíritu particularmente brillante. 
so, de respiración, de movimiento y sentido), ilustrando su propósito con numerosos casos de reviviscencia, fabulosos, históricos o coetáneos, a menudo recopilados en Bruhier, o autores conocidos. Y lamenta los dramáticos errores que ocurren: «..Los ejemplos de personas que después de sacadas de su lecho, amortajadas, llevadas a enterrar o efectivamente enterradas, han vuelto a plena vida, son tan numerosos y de circunstancias tan diferentes ....» ${ }^{10}$. Define la Medicina, como arte o ciencia porque de todo tiene, «que enseña a conservar la salud presente y recobrar, quanto es posible, la perdida». Y en la segunda parte de su Instrucción, desarrollará los medios para hacer volver en sí a los « semi difuntos».

Barnades inspirado sin duda en Winslow cuya disertación sobre los signos inciertos de muerte conoce y cita a menudo, enumera las pretendidas o equívocas señales de muerte, que en realidad son puramente conjeturales. Ni la mutación de color del rostro (la pallida mors de que habla Horacio), ni la falta de brillantez en la niña de los ojos, ni los ojos blandos, marchitos y como flotantes en las órbitas, ni la presencia de espuma en la boca, ni la frustrada aplicación de estornutatorios, vejigatorios o cauterios, ni el no fluir la sangre de las venas abiertas, ni la absoluta frialdad de la superficie del cuerpo, bastan para determinar la muerte verdadera. Igualmente son falsos indicios el calor en lo exterior del cuerpo que puede proceder de una fermentación de humores viciados, el sudor universal o particular, el fluir la sangre espontáneamente o abriendo las venas, la flexibilidad total o parcial del cuerpo.

Recuerda Barnades que Demócrito fue el primero que introdujo en la Medicina esta especie de escepticismo sobre la dificultad de asegurar de manera absoluta 1a muerte de una persona. Winslow y Bruhier opinaban que ninguna señal decidía con certeza la extinción de vida sino la putrefacción incipiente del cuerpo y Feijoo llevaba la duda hasta más lejos, pretendiendo que aun la putrefacción podía engañar...Existía una suma variedad de pareceres sobre las señales distintivas de muerte, pero los médicos hábiles no eran tan escasos de diagnóstico y reglas para discernir si un cuerpo estaba vivo o muerto, decía Barnades. Para él, había dos señales decisivas de estar exánime una persona: 1a sucesiva tiesura de todo el cuerpo, hasta quedar totalmente yerto con las articulaciones en cierto grado inflexibles y la putrefacción incipiente que no había de confundir con la gangrena de una o varias partes del cuerpo. En el largo espacio de 25 años, Barnades había reconocido cadáveres supuestos y sus observaciones le habían cerciorado de que en casos particulares, podían cesar de latir las arterias durante varias horas, como por ejemplo en los asfícticos, suspenderse 1a respiración en las personas pasmadas de frío, quedar unos individuos aquejados de apoplejía o sumidos en profundo letargo, totalmente insensibles a los vejigatorios, sinapismos y sajaduras y que sin embargo se habían recobrado. En cuanto a la tiesura de los miembros, había visto a menudo cadáveres cuyas articulaciones permanecían flexibles y casos de extrema rigidez momentánea en otros sujetos que gozaban de la

10 Instrucción..., parte I, cap.I, p.169. 
vida. Por fin, la formación de una película sobre la córnea transparente del ojo, tampoco era una prueba indudable de muerte, ya que ciertos sujetos arrebatados por una muerte repentina conservaban sus ojos «pelúcidos» y brillantes.

En medio de esta red de incertidumbres y anomalías, concluía, era pues obligación sagrada esperar antes de amortajar un cuerpo y diferir el entierro por lo menos 24 horas. Tras enumerar los distintos modos de morir, terribles y penosísimos, exclamaba: «...No son comparables con la horrorosa y miserable suerte de aquellos infelices que, después de enterrados por muertos, y vueltos en sí, mueren en la misma sepultura... No creo que haya aflicción comparable a 1a calumniosa situación de las personas enterradas vivas... Pues, ¿qué mayor motivo de desesperación que verse una persona fatalmente sacrificada a la Parca, por la inconsideración y precipitación en haberle dado sepultura ? Y si no, ¿ qué más prueba del rabioso despecho que encontrar a los tales, abriendo las sepulturas, descalabrados, roídos, ensangrentados y lastimados en varios deplorables modos? Yo confieso que me horrorizo de sólo pensar tan infeliz y desastrada muerte» ${ }^{11}$. En los países mediterráneos, el riesgo de cometer un error tan atroz se veía aumentado por la costumbre establecida, por razones obvias, de efectuar el sepelio en plazo breve. En España, decía Barnades, los que amortajan a los difuntos no pierden tiempo en prepararlos para evitar de forcejear con articulaciones tiesas del todo, cuando hay casos de convulsiones, de síncopes vehementes o de insultos catalépticos que van acompañados de una rigidez universal del cuerpo que puede durar largas horas. Y deploraba: « ¿Qué no se podrá temer de los acelerados entierros de hoy día, quando no se repara en dar sepultura en el mismo día de la reputada muerte, aunque repentina?» 12 .

Por lo tanto, era el deber de cualquier médico, en ciertos casos de muertes violentas, no abandonar a las personas como difuntas e intentar por todos los medios oportunos hacerlas volver del estado de muerte aparente a plena vida. La teoría de Barnades, compartida por todos los que debatieron del tema, era que hasta en un cuerpo frío como un jaspe ${ }^{13}$, podía quedar algún leve calor en las entrañas, se mantenía un enérgico principio vital en lo interior del cuerpo. Después de la extinción de vida, o muerte verdadera, se observaba en las aberturas anatómicas que perseveraba largo tiempo cierto calor en las entrañas ${ }^{14}$. Era lo que llamaba Barnades «mínima vida» o «vida encubierta» $u$ «oculta vida». Notaba que eran pocos los autores que habían tratado del diagnóstico de «mínima vida», por haber sido omitido este punto en la Semiología médica. Más escasas aun eran las luces sobre el modo de conservar y

11 Ibidem, cap. IV, p. 326.

12 Ibidem, p. 330.

13 Cuerpo «hecho una estatua de puro inmóvil, «hecho un tronco», «tieso como un palo», frío como una piedra, como la misma nieve, como el hielo, como el mármol «son comparaciones usadas con frecuencia para expresar el aspecto cadavérico de la persona que se intenta salvar.

14 Barnades elogia como gran invento el termómetro de Reaumur, pero lamenta que todavía sea de poco uso entre los médicos españoles. 
animar aquellos diminutos restos de vida en casos de aparente muerte. Sólo algunos habían tocado ligeramente esta materia, pero ninguno había indicado la práctica.

Una gran variedad de causas podían arrebatar violentamente la vida a un hombre y dejarle como muerto, cuando solamente estaba sincopizado. Diariamente, en todos los países, ocurrían muchos accidentes de gente ahogada en ríos o pantanos, asfixiada por el tufo de carbón encendido, por el mefitismo del mosto fermentado, de las minas, pozos, sepulcros, muladares, sumideros, latrinas, silos, bodegas, o por el aire rarefacto y malsano de los hospitales o cárceles... Convenía poner en guardia a los médicos sobre el peligro de un fallo de muerte demasiado atropellado, y llamarles la atención sobre todas las operaciones que realizar en el supuesto muerto antes de pronunciarse definitivamente.

Arrancando de la irritabilidad como causa física del movimiento vital y juzgando que los intestinos la conservaban más que otras partes del cuerpo, la Medicina de entonces recurrió entre los socorros recomendados en favor de los ahogados a un procedimiento muy antiguo, aunque algo olvidado: echar en los intestinos de los muertos aparentes una fumigación de tabaco, como estimulante. En sus Praelecciones, Boerhaave establecía una comparación entre el cuerpo de un ahogado y un reloj bien compuesto, pero parado. Si a éste se le da cuerda, decía, y se pone su mecanismo en acción, anda de nuevo. Lo mismo pasa si al que está entre la vida y la muerte, se le estimula adecuadamente... La fumigación de tabaco en los intestinos no era una novedad. Ya a principios del siglo XVII, la practicaban los salvajes americanos de Acadia: llenaban una vejiga de cerdo o una tripa gruesa de humo de tabaco y apretándola con sus manos, la vaciaban en el intestino del ahogado mediante una cánula. Se entusiasmaron pronto los médicos europeos del siglo XVIII. Opinaban que los intestinos por su situación y organización podían reavivar la sensibilidad casi perdida del todo y que por lo tanto, la insuflación de aire caliente, algo áspero como el humo de tabaco, era un socorro muy eficaz y que se debía usar sistemáticamente.

Ciertos medios preconizados por unos autores todavía como colgar de los pies a los ahogados o hacerles rodar en un tonel eran peligrosos y desaconsejables terminantemente, pues se infligía a los cuerpos un tormento inútil y a veces, se producían en ellos lesiones irreparables. Al contrario, las ayudas de humo de tabaco eran muy recomendables y de efecto rápido. Los éxitos conseguidos por aquel procedimiento menudearon, atestiguados por una multitud de observadores de varios países. Con sólo dos pipas, un encendedor y tabaco, se podía socorrer inmediatamente al ahogado, lo que era esencial. El tubo de una pipa se introducía en el ano, mientras que, sobrepuestas las dos cazoletas, alguien soplaba el humo por la segunda pipa. Era, desde luego, un sistema muy rudimentario que tenía sus inconvenientes y mucha incomodidad. Ya en el siglo XVII, el célebre físico maquinista holandés Musschenbroek ${ }^{15}$ y el médico dinamar-

\footnotetext{
15 Pedro Van Musschenbroek (1692-1761), médico y físico holandés, nació en Leyde y fue autor de obras estimadas sobre la electricidad, el magnetismo y la capilaridad.
} 
qués Thomas Bartholin ${ }^{16}$ habían ideado una máquina fumigatoria que luego perfeccionaron Dekkers, Stisser, Heyster, añadiendo válvulas de seguridad, para evitar el retroceso del humo o de otros vapores en la boca del soplador. Gaubius fue el primero que imaginó sustituir la boca por un fuelle. Este medio fue universalmente adoptado y mejorado por unos u otros.

La Sociedad de Holanda que se fundó en Amsterdam en 1767 para socorros de ahogados y asfixiados se valía de una máquina fumigatoria de este tipo, movida por un fuelle. Ninguna nación europea antes de Holanda se preocupó de prestar auxilio sistemático a los ahogados. Juzgando que no mueren tan presto como vulgarmente se cree y que no se les ha de abandonar inconsideradamente por muertos, los holandeses constituyeron aquella asociación respaldada por más de cien personas que contribuían con dos ducados al año en los gastos y efectivamente hubo un número importante de salvaciones. Según se pudo comprobar en las Memorias de la Sociedad publicadas de 1768 a $1772^{17}$, en el espacio de 18 meses recobraron la vida 55 ahogados, tenidos por difuntos. A ejemplo de los Romanos que otorgaban una corona cívica al ciudadano que salvaba 1a vida de su semejante, en una batalla o en otras circunstancias, la Sociedad de Holanda recompensaba al salvador con una medalla de oro de seis ducados que llevaba grabado su nombre.

La empresa caritativa de Holanda produjo inmediatamente numerosos émulos. La Emperatriz de Austria, el duque de Sajonia y los demás príncipes de Europa promulgaron ordenanzas sobre el mismo tema de muertes aparentes y de socorros. Milano y Venecia en 1768, luego Alemania en 1769, imitaron Holanda. Los éxitos de la institución holandesa fueron divulgados en Londres por el Doctor Cohen, quien con la ayuda del Señor Hawes, formó una Sociedad parecida en favor de los tres reinos de la Corona británica. En Francia, ya en 1740, se había publicado un Aviso para socorrer a los que parecen ahogados y se habían difundido por todo el país, ejemplares de aquella instrucción ${ }^{18}$. En 1758 y 1769, se repitió la edición y hubo nueva distribución del folleto en París y en provincias. A partir de la tercera edición de 1769, se preveían fuertes recompensas pecuniarias de 6 a 24 libras en caso de éxito, la mitad sólo en caso de muerte definitiva.

Pero, hubo que esperar hasta 1a fecha de junio de 1772 para la creación en París de un establecimiento equivalente al de Amsterdam. El Preboste de los mercaderes, M. Bugnon, discutió el proyecto con $\mathrm{Ph}$. N. Pia ${ }^{19}$, y su sucesor, M. de la Michodiêre,

16 Tomás Bertholin (1616-1689) pertenecía a una familia distinguida de Copenhague, cuna de varios médicos. Pasó ocho años de su juventud recorriendo Europa. Luego en 1637, estudió en Holanda filosofía, teología, jurisprudencia, arte de curar y árabe. Al cabo de tres años, pasó a Francia (ParísMontpellier), luego a Padua donde se quedó otros tres años. Obtuvo su diploma doctoral en Basilea en 1645. Compuso varias obras e hizo descubrimientos anatómicos sobre los vasos lácteos y linfáticos.

17 Amsterdam, 4 partes en $8^{\circ}$.

18 París, Louvre.

19 Ex boticario y ex regidor de París. 
animado de las mismas miras, ayudó a su realización. Ph. N. Pia perfeccionó la máquina de Bertholin y también redujo a mayor sencillez varias máquinas fumigatorias ideadas en Holanda que se adoptaron en París por su precio módico (12 libras) y su uso fácil que las hacía asequibles, acompañadas de una instrucción clara, a la gente del campo alejada de los socorros. Otros constructores se esforzaron con más o menos suerte, en fabricar nuevos modelos. Un negociante de Lille, M. Hélie, ideó una máquina demasiado complicada para dejar su manipulación en manos de cualquier persona. Constaba de un tubo de cobre horadado lateralmente del cual salía otro tubo curvo que comunicaba con un hornillo exterior, además de un émbolo, una jeringa y dos válvulas. En noviembre de 1774, M. Scanegatty presentó a la Academia de Rouen otra máquina muy parecida a la de Hélie. En Le Mans, M. Ferguson concibió otra. Un cirujano auvernés, M. Clédières, intentó a su vez en 1775 simplificar la máquina de Hélie, pero también su invento tenía un inconveniente: el tubo corto y recto con que se insuflaba el humo lo dejaba enfriarse, lo que no pasaba con el tubo flexible de mayor utilidad.

El que encontró la mejor solución fue Jean-Joseph de Gardanne, Doctor Regente de la Facultad de Medicina de París ${ }^{20}$. Ideó una máquina fumigatoria portátil que se reveló pronto indispensable. Contenía todos los socorros necesarios y la acompañaba una instrucción, sucinta, al alcance de todos. El resultado satisfactorio de su invento determinó el Señor Lenoir, teniente general de Policía de París, a establecer socorros gratuitos en todos los comisariados de la capital, idénticos a los que ya la ciudad mandaba administrar a los ahogados en el Sena. Gardanne fue encargado por el Magistrado de la dirección de aquella fundación. Los sargentos y cabos de los distintos cuerpos de guardia, instruidos y avezados al manejo de los instrumentos que contenía la caja portátil, practicarían los socorros en presencia, sea de Gardanne, sea del Comisario ${ }^{21}$. Muchas naciones europeas se interesaron por el procedimiento. En 1774, ya Londres, Irlanda, Florencia, Turín, Malta habían fundado una Sociedad de socorros a los ahogados. En 1776, el duque de Parma adoptó el método del humo de tabaco en todos sus Estados. En 1773, Ph. N. Pia empezó la relación fiel, año tras año, de los ahogados salvados merced a los socorros administrados, y la publicó bajo el título Detalle de los éxitos del Establecimiento de la ciudad de París en favor de las personas ahogadas ${ }^{22}$.Confirmaba que durante el año 1772-1773, en el espacio de cinco meses, de 20 ahogados socorridos, 16 habían recobrado vida. En 1774, 35 ahogados recogidos con apariencia de muerte, habían sido restituidos a la vida. En 1776, de 36

\footnotetext{
20 Jean-Joseph Gardanne, nacido en La Ciotat (Provenza), era socio de las Academias de Montpellier, Nancy, Marseille y Dijon.

21 Las cajas se podían adquirir en la tienda del librero Rouault, calle del Arpa, por el precio de 12 libras, francas de porte en todo el reino.

22 Amsterdam, París (Lottin, impresor del Rey, calle St Jacques), 5 vols en $12^{\circ}$ y 7 partes. Añadirá todavía en 1789 un suplemento o Resumen de los éxitos .... París, Nyon e hijos, en $12^{\circ}, 2$ partes.
} 
personas de 6 a 75 años sacadas del Sena, 33 habían podido ser reanimadas... Por su celo admirable de Director del Establecimiento, la Sociedad de Amsterdam le condecoró en 1776 con una medalla de oro. En el anverso, se veía un ahogado echado en el arenal, amenazado de muerte por la hoz, y bajo el aspecto de una mujer, la Humanidad que rechazaba la muerte y se disponía a prestar auxilio al infeliz con la caja fumigatoria. LLevaba además la inscripción siguiente Redditur hic enectus aquis patriaeque suisque. En el reverso, otra inscripción rodeada de la corona cívica, decía: Philippo Nicolao Pia, Instituti Parisini submersorum curam gerentis Procuratori, 1776.

La máquina fumigatoria portátil de Gardanne se difundió rápidamente por Francia. Pronto, más de cien cajas que reunían todos los medios de auxilio preconizados, se hallaron en distintos puntos del territorio. Lyon dispuso unas 22 en las orillas del Ródano y del Saona. El cirujano del Rey, M. Faissolle, encabezó la organización. En Rouen, varias cajas se repartieron dentro de la ciudad, bajo la vigilancia del regidor de la ciudad, M. Domay. En La Rochelle, el alcalde se responzabilizó de seis cajas. Las ciudades de Tours, Dieppe, Lille, Beauvais, Abbeville, Valenciennes, Châlons sur Marne, Le Mans, Saint Brieux, Soissons, Poitiers, Valence, Nancy, Dijon, Orléans, Nantes y otras de menor importancia se proveyeron igualmente de la famosa caja de Gardanne, así como muchos hospitales. No sólo las adoptaron en sus dominios ciertos señores de distinción o aristócratas como por ejemplo el duque de la Vrillière o el conde de Moussy, sino también simples particulares. En el ducado de Módena, a partir de 1776, se fabricaron varias de ellas para depositarlas en los hospitales. En Francia, el Consejo de Estado de 14 de marzo de 1776, mandó se extendiesen a las provincias 2258 cajas de socorros a los ahogados en lugar de las 774 que se distribuían antes.

La caja portátil de Gardanne, de cobre rojo cubierto de estaño, tenía una forma parecida a una pipa (por eso se llamó a menudo «pipa de Gardanne») coronada de un capitel al extremo del cual se erguía una pequeña chimenea para dar aire a1 tabaco. A un lado del capitel, salía una punta de cuatro a cinco pulgadas a la que se adaptaba un tubo espiral de latón cubierto de piel blanca y una cánula. Un fuelle estaba fijado en el mango de la pipa. Al lado de la máquina propiamente dicha, se juntaban cuatro paquetes de media onza de tabaco cada uno, una mecha de yesca, un frasco de álkali volátil, otro de aguardiente alcanforado, torcidas de papel, una franela, un gorro de lana, una camisa o túnica para envolver al ahogado. Un folleto con las instrucciones necesarias acompañaba al conjunto.

Pia deploraba el que en todos los países de Europa, incluido Francia, nadie se atrevía a tocar y sacar completamente del agua al ahogado antes de que un comisario de justicia se personase para hacer el atestado. A menudo, éste llegaba tarde para que se pudiese emprender cualquier socorro. Demasiadas formalidades administrativas eran un error muy antiguo y universal que perjudicaba al accidentado. Cuando por fin, se depositaba el cuerpo en el centro de socorros, si no se observaban signos evidentes de corrupción y no se desprendía la epidermis bajo los dedos, siempre conve- 
nía intentar reanimarlo. E1 ceremonial era siempre e1 mismo. Se instalaba al ahogado desnudo en una cama caliente, envuelto en una camisa de franela, se le limpiaba la boca de las sustancias viscosas que la tapizaban con un cepillito suave o una esponja de limpiar dientes, para después practicar el boca a boca o soplarle aire con una cánula de metal. Otro socorrista hacía fricciones con paños mojados en aguardiente alcanforado, se excitaba el interior de la nariz del supuesto muerto con una pluma de ave, o con vapores de álkali o de tabaco sopladas con una cánula. Mientras tanto, se ponía en funcionamiento la pipa y se insuflaba humo de tabaco en los intestinos con una jeringa ${ }^{23}$. Lo sumamente importante era continuar aquellos auxilios sin interrumpir, durante varias horas, sin descorazonarse, hasta cuando ya se percibían unas leves señales de vida. La perseverancia podía salvar al cabo de seis o más horas a personas rescatadas después de una hora o más de inmersión. No faltaban ejemplos irrefutables... Si, con una ligera sangría corría un poco de sangre, la esperanza de salvación era mayor y a menudo, notaban los socorristas, el primer indicio de calor se manifestaba por lo alto de la cabeza.

Gardanne juzgaba nociva la broncotomía que algunos practicaban. Tampoco convenía intentar introducir en la boca del supuesto muerto cualquier emético, ya que estaba parada la deglución, así como las demás funciones. Y desaconsejaba una sangría hasta que el ahogado hubiese recobrado 1a vida. Inútiles del todo eran los estornutatorios, vesicatorios, botones de fuego, cauterios potenciales y sinapismos. En el estado de postración e insensibilidad del cuerpo, no hacían impresión alguna. Durante cierto tiempo, se había acreditado usar de unas gotas de álkali fluor en la lengua del ahogado, pero era peligroso y en varias ocasiones, se había comprobado que tenía el grave inconveniente de quemar la lengua y las mucosas de la boca, lo que podía degenerar en gangrena. Bastaba presentar el álkali volátil bajo la nariz. Mucho más eficaz que cualquier sustancia irritante para reanimar el organismo sumido en atonía general, era la lavativa de humo de tabaco ${ }^{24}$. Conforme volvía en sí el ahogado, manifestaba movimientos convulsivos de las quijadas que podían provocar roturas de dientes y lesionar la lengua. Para prever estos accidentes, era preciso introducir entre los dientes unos trocitos de corcho o palitos de malvavisco o de raíz de regaliz.

Pronto la noticia del invento de Gardanne se difunde en España y varias publicaciones relativas a la reviviscencia de los ahogados nacen. La Gaceta de Madrid de

\footnotetext{
23 Ciertos médicos, para vigorizar el calor natural casi enteramente extinguido por cualquier accidente, recomendaban envolver al enfermo en la piel de un cordero recién desollado. Un lecho de cenizas calientes o de estiércol de caballo eran igualmente de uso bastante corriente.

24 Barnades alude de paso a la introducción del humo de tabaco «por abajo» y cita a menudo como poderoso irritante los polvos de raíces de vodegambre, hierba cuyo zumo secado al sol, usaban antiguamente los ballesteros de España fregando con él sus ballestas, a cuya venenosa herida moría inevitablemente el ganado. Por eso, dicha hierba se llamaba «hierba del ballestero». Barnades no habla en su Instrucción de las máquinas fumigatorias ni de la de Gardanne, novedades posteriores a la redacción de su tratado.
} 
1775 anuncia la nueva máquina fumigatoria portátil. Ya aquel mismo año, el Doctor D.Christóbal Fabregat da a luz pública en Madrid, Valencia y Barcelona su Discurso médico sobre el modo de socorrer y restituir al uso de sus sentidos los ahogados, helados y sofocados por el tufo de carbón, de la cal, de las velas de sebo, del vino quando fermenta y de otras exhalaciones perniciosas ${ }^{25}$. En 1776, sale conjuntamente en Madrid, Sevilla, Cádiz, Valencia y Barcelona e1 Discurso médico de las señales que distinguen el hombre verdaderamente ahogado del sumergido en las aguas después de muerto y modo más verosímil de encontrar el motivo de su muerte, redactado por el médico D. Cristóbal Nieto de Piña. La Gaceta de Madrid de 18 de junio de 1776 relata un accidente ocurrido en París el 3 de junio. Cayó al Sena un albañil. Dos pescadores le sacaron del agua al cabo de media hora con aspecto de muerto. Se le condujo al cuerpo de guardia inmediato donde le prodigaron los socorros establecidos por la Policía en estos casos de muerte aparente, y en especial la pipa de Gardanne. En tres horas, se logró su perfecto restablecimiento. La misma Gaceta de 18 de junio de 1776 menciona una Instrucción sobre el modo y medio de socorrer a los ahogados, compuesta de orden del Hospital Real de Nuestra Señora de Gracia de Zaragoza, que se vende en 1a librería madrileña de Escribano, calle de Atocha. Por su parte, y anteriormente, la ciudad de Sevilla ha informado al público de la máquina fumigatoria con un folleto titulado Instrucción sobre los medios de socorrer a los que se ahogaren o hallaren en el río de Sevilla ${ }^{26}$. En Valencia también, en 1776, Nicolás Fabregat publica un Discurso médico práctico sobre el modo de socorrer y revocar a sus sentídos a los ahogados ${ }^{27}$. En 1779, sale en Mallorca, una Breve instrucción del modo y medios de socorrer a los muertos aparentes que se llaman asphíticos, compuesta por José LLabrés ${ }^{28}$.

La «pipa de Gardanne» encuentra admiradores entusiastas en toda España. En Barcelona, el Doctor D. Josef Ignacio Samponts, socio fundador de la Academia médico práctica de la ciudad y su primer Secretario, compone en 1777 una prolija Disertación médico práctica sobre las muertes aparentes y sus remedios en la que describe la famosa caja portátil ${ }^{29}$. Francisco Milans la fabrica y la vende por 54 reales en casa de Francisco Fornolls, mancebo cirujano, plazuela de San Francisco, acompañada de la Disertación que cuesta 3 reales. El mismo modelo se puede adquirir en la librería barcelonesa de Francisco Rivas, plaza de San Jayme y asimismo en la librería madrileña de Copín, carrera de San Jerónimo. A principios del año 1778, Samponts ofrece un premio de 30 pesos sencillos o sea de 240 reales a la primera

25 Madrid (Esparza, Puerta del Sol), Valencia (librería de Bernardo Francés), Barcelona (librería de Carlos Zapera)

26 Sevilla, Jerónimo de Castilla, $4^{\circ}, 32$ págs.

27 Valencia, Francisco Burguete, 62 págs.

28 Mallorca, Joaquín Jaquetot y Rafael Evinent, 28 págs.

29 Barcelona, Francisco Generes, $1777,4^{\circ}, 10$ capítulos. 
persona que en todo el año corriente restituya la vida dentro de España a algún recién nacido, sofocado, ahogado o en estado de alguna de las muertes aparentes. El premiado fue el cirujano del hospital de Cartagena, D. Antonio Ortiz, quien logró hacer volver en sí a dos hombres. Uno, caído al mar a donde llevaba sus mulas, recogido sin pulsos ni calor vital, con manchas amoratadas en las espaldas, pecho y rostro, y con los ojos hundidos. Recobró la vida muy lentamente, al cabo de poco más de una hora. El otro, sofocado a1 limpiar un pozo de inmundicias, se quedó dos horas como cadáver antes de aplicarle los remedios preconizados por Gardanne y se salvó.

El Ayuntamiento de Barcelona resuelve en 1779 costear el precio de dos máquinas fumigatorias que se depositarán en dos parajes adecuados (una al cuidado de Gabriel Marsal, cirujano supernumerario de la Sanidad, bien instruido en su uso, otra, por las contingencias que puede haber en la Marina, en manos de Onofre Segarra, teniente de guardián del puerto, que vive en la Barceloneta) ${ }^{30}$.

Samponts reivindica su calidad de propagador en España de la máquina de Gardanne y en una carta que dirige a los editores del Memorial Literario de septiembre de $1788^{31}$ las toma con un colega, el médico aragonés de Agüero, D. Serapio Sinués. Éste acababa de expresar en el mismo periódico el deseo de que se extendiese por todos los pueblos de España el uso de la máquina fumigatoria. Recuerda Samponts que hace más de diez años, él tuvo la misma idea y publicó una disertación sobre los distintos tipos de muertos aparentes y la manera de revocarlos a la vida, terminando su protesta con esta frase irónica : «Al Señor Sinués, se le habrá escapado...»

En su Gaceta de Salud ${ }^{32}$ que inicia en 1773, Gardanne refiere una multitud de salvaciones ocurridas en Francia y otros países de Europa gracias al método del humo de tabaco. Por su parte, Pia en sus Detalles de los éxitos... cita ya en 1774, el caso de un crío de 20 meses que en Priego (Córdoba ) el 9 de agosto cae de una ventana a un canal. Cuando al cabo de media hora, su padre logra rescatarlo, parece muerto. Le aplican los remedios recomendados por Gardanne y el niño recobra vida y mama. Esta fecha de 1774 es la prueba indubitable de que muy rápidamente estuvo España enterada de lo que se practicaba en Francia y lo aplicó en muchas ocasiones. La Gaceta de Madrid se hace lenguas de la utilidad de la máquina fumigatoria y recalca repetidas veces la necesidad de que la haya en todos los pueblos. A lo largo de los años, relata casos sorprendentes de reviviscencia de ahogados, confirmados en distintos puntos de la península o en las Baleares, de los que daremos unos ejemplos:

Lebrija (abril de 1777): Un niño de cinco años cae en un pozo de agua de once varas de profundidad donde permanece más de una hora. Se 1e saca cadavérico. El

30 Gaceta de Madrid, 27 de agosto de 1779.

31 Memorial Literario, Parte II, p.494.

32 Gazette de Santé (1773-1776- 1784), París, 2 vols. en $4^{\circ}$. 
médico D. Pedro de Campos, le desnuda, le coloca sobre cenizas calientes y le insufla en narices e intestinos humo de tabaco. El niño se restablece ${ }^{33}$.

Trujillo (enero de 1779): Un chico de siete años y medio, al coger un trozo de hielo, cae en un charco. Cuando el cirujano D. Joaquín Labordera empieza a asistirle, está sumamente frío, sin pulso ni respiración, con los ojos abiertos y opacos. En dos horas, por medio del humo de tabaco, le restituyó su entero conocimiento y en ocho días, estuvo el muchacho perfectamente restablecido ${ }^{34}$.

Marbella (enero de 1782): Un niño de nueve años cae en un pozo de once varas y medio de alto y dos y media de agua, hiriéndose en la cabeza. Al cabo de tres cuartos de hora, logran extraerle con garfios, lesionándole en un pie. Llaman a D. Francisco Sarget y Serrá, cirujano mayor del Regimiento de Caballería de la Reina. Los socorros corrientes (cama caliente, friegas con aguardiente alcanforado en todo el cuerpo, álkali volátil debajo de la nariz), todo resulta inútil. El cirujano carecía de la máquina fumigatoria, pero no se desanimó y usó de dos pipas para introducirle el humo de tabaco en los intestinos. A los 49' de practicarle dichos auxilios, y haciéndole oler por segunda vez el álkali, el niño movió la cabeza, empezó a llorar y a menearse en términos que fue preciso sujetarle. Unas gotas de álkali desleídas en agua, el vendaje de las heridas y una sangría completaron la cura. A las 16 horas de haber caído en el pozo, el rapaz se halló fuera de todo cuidado ${ }^{35}$.

La Gaceta de Madrid de 19 de abril de 1791 relata la generosa iniciativa tomada en Orihuela por el canónigo lectoral Dr. D. Marcelo Miravete. Este sacerdote, compadecido de los numerosos infelices que caían en el río Segura en que perecían sin recibir un eficaz auxilio para recobrar sus sentidos, decidió usar parte de sus rentas en formar una Junta para socorrer a los ahogados en el Segura, en las acequias y pozos inmediatos, como también a los sofocados, a los acometidos de muerte repentina y demás asfícticos. Se componía la Junta de un cirujano director, dos médicos, dos ayudantes y un sustituto que tenían a sus órdenes dos nadadores para sacar del agua a los ahogados y tres «convocadores» conductores que daban inmediato aviso de la desgracia ocurrida y llevaban a los pacientes al paraje señalado para la administración de socorros. Todos ellos gozaban de un estipendio fijo y de gratificaciones complementarias eventuales, según los casos. Todo venía costeado a expensas del benéfico clérigo así como la Instrucción impresa que había compuesto para prevenir los lances que podían ocurrir, el modo de operar y las obligaciones de la Junta. Además, había encargado en Cádiz una excelente máquina fumigatoria con todos sus instrumentos y accesorios (cigarros habanos, aguardiente y álkali volátil) que cedería al Ayuntamiento después de su muerte. El Ayuntamiento aceptó con gratitud la manda, alabando la humanidad que manifestaba el canónigo con sus conciudadanos. Y el

33 Gaceta de Madrid, 27 de septiembre de 1777.

34 Ibidem, de 19 de febrero de 1779.

35 Ibidem, 15 de febrero de 1782. 
Rey, enterado de todo por su Secretario de Estado, conde de Floridablanca, se sirvió expresar al Dr. Miravete, lo grato que le había sido su rasgo de patriotismo.

Entre los casos más excepcionales de reviviscencia de ahogados, recordaré lo que ocurrió, en 1774 durante el naufragio del barco que conducía de Francia a Inglaterra al famoso oculista Wincel, experto en operaciones de catarata, conocido en toda $\mathrm{Eu}$ ropa, acompañado de su familia. Sacaron del mar a su esposa a la una de la tarde, sin apariencia de vida. El Doctor Alexander Johnson le administró todos los socorros posibles, pero sólo a las nueve de la noche, dio las primeras señales de vida y se restableció perfectamente ${ }^{36}$.

La máquina portátil de Gardanne, reputada por la más sencilla, la más cómoda, la más barata, la más resistente y duradera de cuantas se habían inventado, servía también para los asfixiados, ahorcados, recién nacidos aparentemente muertos o gente tocada del rayo. Era preciso, decían los médicos, distinguir en las asfixias las provocadas por mofetas o vapores mefíticos y las originadas por un afecto «histérico» que se desvanecían por sí solas. La asfixia o privación repentina de pulso, respiración, movimiento y sentido podía proceder de causas múltiples: vapores del vino, cidra, cerveza y otras materias vegetales fermentadas, olores fuertes que calan hondo como por ejemplo en bodegas donde se conservan aceites, sebos, sustancias grasas para las jabonerías, aguarrás, agua salada corrupta. Se contaba el caso que ocurrió en un buque llamado «El Camello» que regresaba de Cádiz. Un marinero quiso destapar un tonel de agua de mar y cayó fulminado. Sus compañeros y el cirujano también perdieron el conocimiento al intentar prestarle auxilio. Unos marineros holandeses igualmente fallecieron por las exhalaciones potentes de unas sustancias aromáticas que transportaba su barco. Los pozos negros, sumideros, letrinas, vertederos, tumbas, cementerios, fuegos fatuos, emanaciones de minas de metales o de carbón que, al contacto de las lámparas de los mineros, provocaban a veces explosiones de grisú (se habían visto mineros caer de repente de las escaleras por las cuales intentaban salvarse), hasta flores putrefactas en una habitación cerrada, podían asfixiar con sus vapores endormecedores. Decía Boerhaave en su tratado de las enfermedades nerviosas, al hablar de este tipo de muerte aparente: «Restituid el movimiento parado y restituiréis la vida a los asfícticos, porque todo está suspenso, nada está destruido del todo».

\footnotetext{
36 Además de los socorros ya señalados, el Dr. Johnson recomendaba en sus Instrucciones ... como muy eficaz en muchos casos, colocar al ahogado desnudo entre dos personas sanas, igualmente desnudas, de fuerte temperamento y notable calor natural que tendrían que aplicar la parte delantera de su cuerpo contra las dos caras del cuerpo del supuesto muerto, friccionándolo y meneándolo continuamente al mismo tiempo. El Dr. Haen, médico de la Reina de Austria, era también partidario de aquel método de comunicación de calor.
} 
Ya en 1774, había publicado Gardanne un Aviso al pueblo sobre las asfixias o muertes aparentes o repentinas ${ }^{37}$ al que aludió repetidas veces la Gaceta de Madrid hasta 1785 y que tuvo nueve ediciones. Lo vertió al castellano en 1784 el profesor de medicina D. Juan Galisteo Xiorro y lo despachó Francisco Fernández en la Corte. En una recapitulación concisa, Gardanne inculcaba los principios básicos para salvar a las víctimas y al final del libro, expresaba el deseo de que los curas en sus predicaciones dominicales, hiciesen lectura de él. Preveía componer almanaques para la gente del campo que quisiese informarse. Tras exponer los seis tipos de asfixias que podían ocurrir a lo largo de las estaciones del año, contaba que había consultado a varios escritores que habían tratado del mismo tema, entre otros a Morand, médico de Nancy ${ }^{38}$, Vicq d'Azyr ${ }^{39}$, Maret ${ }^{40}$, Parmentier, así como a varios científicos de Holanda y de Italia y sobre todo a Cadet de Vaux ${ }^{41}$ que le comunicó sus propias reflexiones sobre los aires mefíticos y le dio acceso a su biblioteca.

La Sociedad Económica de Palma de Mallorca había comprado en 1783 varias máquinas fumigatorias y encargado a tres médicos una instrucción para su manejo. Gracias a una de ellas, se salvó el criado del cónsul de Francia, aquejado de un «sopor apopléctico». En Esporlas (Palma de Mallorca), en abril de 1783, dos hombres se asfixiaron en el fondo de la cisterna que querían limpiar y sólo se pudieron sacar una hora después. El cirujano D. Salvador Llinas, encargado de la máquina en aquel pueblo, aplicó los socorros. Al cuarto de hora, un hombre volvió en sí. El otro permaneció una hora y media sin señales de vida, pero con las ayudas de humo de tabaco, recobró por fin los sentidos ${ }^{42}$. En varias regiones de España, se va acreditando el método de Gardanne y los periódicos y noticiarios relatan curas milagrosas acá y acullá. Así en Baena, en febrero de 1790, el cirujano D. Pedro Laguna ${ }^{43}$ comprobó una vez más la eficacia de la pipa de Gardanne cuando un hombre que había bajado a un pozo de la Almedina para recoger una porción de esparto, cayó fulminado por el vapor mefítico. Una prima suya, con espíritu varonil, bajó a su socorro, pero padeció

37 Gardanne, París, 1774 , Rouault en $12^{\circ}, 114$ págs. $8^{\circ}$ edición, París, 1781 , Imprenta Valade, en $8^{\circ}$, 160 págs.

38 Socio de la Academia de las Ciencias y Dr. Regente de la Facultad de Medicina de París, Morand compuso en 1776 una obra sobre las minas de carbón y las asfixias que provocaban los vapores del carbón. Preconizaba el humo de tabaco para reanimar a los ahogados y asfíticos.

39 Félix Vicq d'Azyr (1748-1794), primer médico de la Reina, anatomista distinguido y desde 1774, socio de la Academia de las Ciencias, era profesor en la Escuela Veterinaria de Alfort.

40 Este médico, secretario de la Academia de Dijon, publicó en 1777 una breve memoria de 26 págs relativa a las personas aparentemente muertas, pasmadas de frío o asfixiadas del tufo de carbón. El también recomendaba el uso de la máquina fumigatoria.

41 Antoine Cadet de Vaux (1743-1828) trabajó mucho tiempo con Parmentier sobre problemas de salubridad pública y fundó en 1777 el Diario de París.

42 Gaceta de Madrid, 18 de abril de 1783.

43 Pedro Laguna era oculista y había sacado la catarata a más de cien personas. 
la misma desgraciada suerte. Otro hombre y un esclavo negro del conde de Pozos Dulces, también intentaron rescatar a los anteriores, pero se quedaron exánimes en el fondo. El cirujano animó a los concurrentes para sacarlos del agua a lo cual se resolvió uno de ellos, ayudándose con una soga. Los primeros extraídos, un salvador y la mujer, con los socorros recomendados de Gardanne, volvieron por grados a respirar y recobrar el conocimiento. El esclavo se desprendió dos veces de la cuerda y se lastimó gravemente Falleció así como el primer caído que tardó varias horas en sacarse ${ }^{44}$. Otro caso parecido se produjo en 1777, en Puebla de San Salvador (provincia de Cuenca). Tres hombres que habían bajado a un pozo que tenía un depósito de heces para hacer aguardiente, se quedaron sofocados del tufo. Los dos primeros se sacaron al cabo de media hora, el tercero al cabo de diez minutos. El cirujano de la villa, Juan Custodio López y el médico D. Bernardo Cazador, conocedor del método de Gardanne, les dieron humazos, los rociaron con vinagre y les administraron friegas. Uno de ellos tardó dos horas en volver en sí. Al día siguiente, los tres estuvieron fuera de peligro ${ }^{45}$.

El Memorial Literario relata en 1794 varios casos de asfícticos socorridos con la maquina fumigatoria en Belmonte ${ }^{46}$. Recordaré unas circunstancias particulares en que también, según nos cuenta la Gaceta de Madrid, obró de maravilla la «pipa de Gardanne». En Tarancón, un pastorcito de quince años, un día tormentoso de junio, fue herido por una centella a las cinco de la tarde. El rayo le quemó la ropa y la montera, deshizo el alambre del rosario que llevaba al cuello, le quemó el pecho y todo el lado izquierdo hasta la ingle, y del lado derecho, la mitad del muslo y la pierna hasta el talón, dejándole yerto como el mármol. El Doctor D. Juan Antonio Pascual y Rubio, socio de la Real Academia médica matritense y médico titular de la villa, practicó los socorros que prevenía Gardanne y consiguió que a las diez de la noche, el muchacho diese señales de vida. A las seis de la mañana siguiente, articuló algunas palabras y estuvo entonces fuera de peligro ${ }^{47}$. El día 23 del mismo mes de junio de 1779, provocó el rayo terribles estragos en Burgos. Cayó sobre la Plaza Mayor, se introdujo por el tejado de una casa e hirió a una mujer de 40 años muy robusta, arrojándola al suelo como muerta. El Doctor D. Joseph Fernández Vega le administró los socorros recomendados y la mujer recobró pulso y calor vital al cabo de diez horas. Sufrió grandes quemaduras, pero caminó felizmente hasta su curación ${ }^{48}$. El humo de tabaco se aplica igualmente a los recién nacidos sin movimiento. En 1775, D. Juan de Irigoyti, ex cirujano ayudante mayor de los Ejércitos, individuo de la Real Sociedad Bascongada y cirujano en la Corte, usa el método de Gardanne y ha asistido a varias mujeres. Cuando en Aranjuez en 1775, después de un parto muy difícil y doloroso,

44 Gaceta de Madrid, 15 de febrero de 1791.

45 Ibidem, 23 de septiembre de 1777.

46 Memorial ... Parte II, septiembre.

47 Gaceta de Madrid, 29 de junio de 1779.

48 Ibidem, 28 de septiembre de 1779. 
Maria Serrano da a luz un niño con toda la apariencia de muerto, el cirujano D. Eugenio Molero, estimulado por el segundo médico del Real Sitio, D. Matías de Alcalá, echa mano de los remedios preconizados para los sofocados y ahogados, especialmente el humo de tabaco. Al cabo de dos horas, el niño lloró y cinco horas después, tomó el pecho. Gozó luego de perfecta salud ${ }^{49}$.

La teoría del humo de tabaco alabada por Gardanne para la reviviscencia de ahogados y asfixiados, y que se adoptó en toda Europa, tuvo su detractor en la persona del Doctor Antonio Portal ${ }^{50}$. Este negaba la propiedad de las lavativas de tabaco para reanimar el resto de principio vital, y decía que hinchaban demasiado el bajo vientre sin provecho alguno. El era partidario de la traqueotomía que condenaba Gardanne. Nació una polémica, pero cada uno se quedó en sus trece.

Pretendía Gardanne que su máquina portátil podía salvar a los asfixiados por el tufo del carbón y se dieron casos efectivamente en que se reveló eficaz, como en 1779 en Barcelona, cuando la familia de un cuchillero (marido, mujer, hijo de 13 años) y un aprendiz se quedaron intoxicados y como muertos. La mujer y el joven fallecieron, pero los demás se curaron, con los socorros de la máquina fumigatoria y el álkali ${ }^{51}$. Pero existía otro procedimiento que usaban preferentemente ciertos médicos. Estos opinaban que, a diferencia de los ahogados que hay que recalentar sin tregua, los asfixiados se curan por el agua que viene a ser el verdadero específico contra las mofetas. Este método para resuscitar a personas asfixiadas con agua fría era muy antiguo. Ya conocido por los griegos que lo practicaban así como el boca a boca y mencionado por Lucrecio en su poema De natura rerum era constantemente recordado por los autores que habían tratado del tema, como un socorro a menudo coronado de éxito. Boerhaave lo preconizaba. Se recomendaba pues, sacar al asfixiado al aire libre, apenas vestido, y echarle cubos de agua fría con fuerza y sin parar en el cuerpo y cara, bajo la nariz, largo tiempo, varias horas si necesario, hasta que diese alguna señal de vida. Los Rusos no vacilaban en echarlo en la misma nieve, frotándole con ella el estómago y las sienes y continuando estos auxilios hasta que desapareciera el color lívido del cuerpo. El recobro de vida se manifestaba por pequeños hipos, encogimiento de las ventanas de la nariz, vómitos de vez en cuando de flemas espesas y espumosas, hasta de materias negras. Los vómitos iban seguidos de un

49 Ibidem, 12 de diciembre de 1775.

50 El barón Antonio Portal (1742- 1832) nació en Gaillac (diócesis de Albi). Estudió en Monpeller, se afincó pronto en París, ingresó en la Academia de las Ciencias en 1769, fue profesor en el Colegio de Francia y Presidente de la Academia de Medicina. Publicó muchas obras, algo olvidadas hoy. Todavía es digna de estimación su Historia de la anatomía y de la cirujía, París, 1770-73, 7 vols. en $8^{\circ}$. Fue médico consultor de Luis XVIII y de Carlos X. Falleció en París el 25 de julio de 1832. Su Instrucción sobre e1 método de curar a los ahogados sofocados..., escrita en 1796 (1 tomito en $8^{\circ}$ de 157 págs.) e impresa a expensas del directorio ejecutivo, fue vertida al castellano por el presbítero D.Guillermo Augusto Jaubert (Salamanca, 1798).

51 Gaceta de Madrid, 5 de febrero de 1779. 
temblor general, signo precursor de la respiración. Convenía echar agua fría hasta que el asfixiado diese gritos y articulase alguna palabra. Luego, algo repuesto, entraba en una como modorra y se le llevaba a una cama caliente para friccionarle enérgicamente. A menudo, el enfermo notaba un gran dolor de cabeza que se iba calmando con una cataplasma de miga de pan, arroz y vinagre. Por fin, se le daba de tragar seis cucharadas de aguardiente y 30 gotas de álkali volátil por cucharaditas cada cuarto de hora. Aseguraban los médicos del XVIII que con agua fría, se salvaban personas tras 15,16 y más horas de muerte aparente, al cabo de 5 o 6 horas de socorros continuos. El mismo tratamiento valía para las insolaciones.

La Real Academia de Medicina matritense no se oponía al método rudo y drástico aconsejado ni tampoco lo juzgaba obsoleto. Lo confirmó en la junta de 16 de noviembre de 1792, cuando se leyó la Memoria médico práctica sobre que las irrigaciones de agua fría sobre la cabeza son remedio de la insolación, compuesta por D. Pedro Francisco Domenech y Amaya, médico de la villa del Almendral (Extremadura) ${ }^{52}$. En 16 folios en $4^{\circ}$, relataba el médico tres casos ocurridos en julio y agosto en las cuerdas de presidiarios que en 1787 y 1788 habían pasado por la villa. El primero (un hombre de unos 30 años), fulminado por el sol, recibió 36 cántaros vertidos sin intermisión durante 4 horas, pero no fue posible reanimarlo. El segundo, en la cuerda de agosto de 1788, cayó soporoso a la entrada del pueblo. Se le echaron 40 cántaros de agua fría sin resultado. Eran las cinco de la tarde y otras tantas las llevadas en socorrerle. Se le extrajo libra y media de sangre del brazo que salió bastante encendida y gruesa. Al cabo de 5 minutos, no abandonando los riegos, se hizo otra evacuación de dos libras de sangre de la vena frontal. A las seis de la tarde, habiendo consumido ya 66 cántaros de agua, el enfermo se estremeció. Se le puso ropa enjuta y bebió un jarro de agua. Al cabo de un cuarto de hora, tuvo un furioso vómito de copiosa bilis porrácea y experimentó un violento dolor de cabeza. Luego, inició un sueño tranquilo acompañado de abundante sudor. Al día siguiente, fue conducido a su destino sin otra novedad. En la misma cuerda, pero dentro de la cárcel, otro joven presidiario como de 23 años, fue acometido del mismo afecto soporoso. A los 14 cántaros, volvió en sí. El Académico Mociño que era el censor del escrito, juzgó las observaciones de Domenech muy buenas y dignas de publicarse.

Volviendo ahora a la caja fumigatoria de Gardanne, objeto esencial de este propósito, ya sabemos que encerraba un frasco de álkali volátil fluido. No era propiamente dicho un específico reservado a la cura de los ahogados y asfixiados, sino un accesorio, pero se reputaba ser uno de los estimulantes más poderosos, preferible a los demás. Bastaba con darlo a respirar del pomito aplicado a 1a nariz para provocar una reacción. El álkali fluido, llamado también álkali volátil saponáceo, agua de luz o

\footnotetext{
52 Pedro Domenech y Amaya, natural del Almendral (provincia de Badajoz) se había graduado en Sevilla y había sido autorizado por el Protomedicato el 22 de diciembre de 1781, a ejercer la medicina.
} 
asta de ciervo, era un espíritu de sal amoníaco que preparaba según un método propio el químico francés y Académico de las Ciencias de París, M. Sage ${ }^{53}$. Enterada España de la pureza sin par del álkali de Sage, informó al público en la Gaceta de Madrid de 21 de octubre de 1777 que saldría en breve la traducción en castellano de la obrita que acababa de publicar el químico francés sobre sus propias experiencias y en la que se indicaban las dosis que recetar en casos determinados. Efectivamente, ya en febrero de 1775, estuvo lista la versión del tratadito y se despachaba gratis en las boticas de la calle ancha de San Bernardo y de la calle de la Montera de Madrid, acompañando los frasquitos de cristal del álkali que se vendían a 12 reales cada uno. El conjunto podía también remitirse por correo ${ }^{54}$.

Gozó inmediatamente de gran aceptación el nuevo remedio que se revelaba eficaz en muchísimos accidentes: apoplejía, desvanecimientos de cabeza, síncope e insultos soporosos, mordeduras de víboras o de animales rabiosos, picaduras de insectos y sabandijas ponzoñosas, quemaduras, sofocos por mofetas, accesos epilépticos... Se recogieron en la prensa diversos testimonios, certificaciones y documentos fidedignos por los cuales constaba que con el uso del expresado remedio, se habían curado varias personas en distintas provincias de España. Cuando oler el álkali no bastaba para que se recuperase el enfermo, se le administraba interiormente el licor desleído en agua y según dosis establecidas por Sage. De 1775 a 1783, época del mayor entusiasmo suscitado por aquel milagroso remedio, menudearon en la Gaceta de Madrid, curas edificantes. En El Viso, un 7 de junio de 1778, un hombre sufrió un accidente apopléctico a las 12 de la mañana y se quedó privado de sentido y movimiento. Los estimulantes corrientes no surtían efecto. A las cinco de la tarde, se usó el álkali volátil fluido que la caridad del marqués de Santa Cruz había depositado en poder de los párrocos de su estado. Inmediatamente, dio señales de movimiento y con una segunda administración, logró hablar. Al tercer día, se halló perfectamente bueno y desde luego, prosiguió en su profesión de arnero sin la menor novedad ${ }^{55}$. En Carmona, en 1779 , cuatro curas milagrosas se consiguieron merced al álkali en personas aquejadas de distintos males. El primero citado fue un monje carmelita descalzo que tuvo una repentina apoplejía convulsiva. D. Cándido María Trigueros de la Real Academia de Buenas Letras de Sevilla y de la Real Sociedad de Amigos del País de Sevilla le asistió con el Doctor titular D. Bernardo Oviedo. Le administró en tres tomas 15 gotas del espíritu desleído en agua, y le puso paños mojados en él, en la parte del cerebelo. A las 50 horas del accidente, se repuso completamente el monje. El segun-

53 El químico Balthasar-Georges Sage (1740-1824), discípulo de Nollet y de Rouelle, fue profesor de mineralogía experimental en 1778, y director de la Escuela de las Minas en 1783. Adversario de los principios de la Revolución, perdió más tarde su cátedra. Entre otras obras, compuso Elementos de la química docimástica, París, $1772,8^{\circ}$, ampliada cinco años más tarde en 2 vols. en $8^{\circ}$.

54 En 1780, se hizo segunda edición de su tratadito.

55 Gaceta de Madrid, 14 de julio de 1778. 
do que recurrió a Trigueros fue un rabadán mordido en un dedo por un perro rabioso. Trigueros le aplicó en el dedo un cabezal mojado en el álkali fluido y dispuso con aprobación del médico D. Joseph Mexía, socio de las Reales Sociedad Médica y Patriótica de Sevilla que, por espacio de cuatro días, bebiera tres veces 12 gotas de álkali desleídas en tres onzas de agua. Se curó perfectamente. El tercer caso concierne al hijo de un cirujano retirado de los Reales Ejércitos que se veía molestado por un tumor linfático en el cuello, que iba endureciéndose como piedra. Su padre añadió a las cataplasmas, de seis gotas de álkali hasta diez. Con sólo dos dosis, se deshizo el tumor $^{56}$. En cuanto a un trillador al que picó una tarántula, estuvo a punto de fallecer y se le administró los Santos Sacramentos. E1 cirujano Francisco Díaz de Ojeda no se desanimó. Puso cabezales empapados en el álkali sobre la picadura, las articulaciones y las partes más dolorosas del cuerpo y tras dar de tragar al moribundo 6 gotas del licor desleído en dos onzas de agua, observó un notable alivio en su estado. Aumentó las dosis en 15 gotas en cinco tomas, y al cabo de tres horas, el trillador se encontró fuera de peligro $^{57}$. En Calatayud, durante el invierno de 1780, un padre trinitario, un lego y un sacristán se encontraron privados de sentido y movimiento por culpa del tufo de un brasero. Los cirujanos llamados a su auxilio lamentaron que no hubiese en la ciudad la máquina fumigatoria «cuyos saludables efectos están acreditados con repetidas experiencias en otros pueblos dentro y fuera del Reino» y con sólo el álkali, unas sangrías y los socorros corrientes, lograron hacer volver a la vida e1 sacristán, los otros no. Las Gacetas de 29 de mayo, 6 y 16 de junio de 1780 recogen en una lista el número de personas salvadas en distintos puntos de la península (Tortosa, Villafranca de Extremadura, Chiclana, Fuentes de la Campana, Puerto Llano, Almadén, Mendivil de Alava, Cádiz, Braojos, Ubeda), con las circunstancias exactas del accidente (6 apoplejías, 2 mordeduras de tarántula, 3 de víbora, 1 de alacrán, 1 epilepsia), amén de una niña de 15 meses que se quedó sin movimiento y de dos hombres ahogados en un silo de cebada que permanecieron cerca de hora y media sofocados por el vapor mefítico (de éstos, sólo uno se salvó). Todas estas curas vienen certificadas por los médicos o cirujanos cuyos nombres se precisan, que atendieron a los enfermos. Lo mismo pasa en 1781 en Badajoz con un hombre apopléctico restablecido en el espacio de cuatro días con las dosis de álkali preconizadas por Sage y en La Guardia con una chica de 20 años, víctima de una grave indigestión. En Avilés, desde fines de mayo hasta fines de septiembre de 1781, el médico titular D. Antonio Sánchez logra la reviviscencia de siete personas, entre ellas dos criaturas de tres años ${ }^{58}$.

Todos estos ejemplos prueban hasta qué punto gozó de gran notoriedad el álkali volátil fluido de Sage, juzgado capaz de sustituirse favorablemente a la máquina cuando ésta no existía en ciertos pueblos. La fama del milagroso licor no decayó en

56 Ibidem, 9 de abril de 1779 .

57 Ibidem, 8 de junio de 1779 .

58 Gacetas de Madrid, 6 de julio, 31 de julio y 4 de diciembre de 1781. 
los años siguientes. En 1784, el Doctor D. Joseph Orozco, leyó en la Sociedad Económica de Lugo una memoria sobre su uso y sus virtudes y la Sociedad resolvió depositar en todos los distritos de la provincia frasquitos de álkali cuyos gastos franquearían los socios. Pero, no por eso, se había desechado la máquina de Gardanne. En 1787, la Real Sociedad Económica de Tárrega, en su junta pública y general de 4 de noviembre, presidida por el conde del Carpio, recibió de D. Jacobo María Espinosa, Oidor de la Chancillería de Granada, e1 regalo de cuatro máquinas fumigatorias, acompañadas de un ejemplar de la Disertación médico práctica de Samponts. La Gaceta de Madrid de 10 de febrero de 1792 menciona el método de Gardanne y señala que se aplica también en Suiza. Y todavía en 1795, D. Felix Pérez Arroyo, cirujano hernista de los Reales Hospitales de Madrid, que vivía en la calle de la Visitación, seguía construyendo máquinas fumigatorias.

Dado que se difundió por toda Europa el método de Gardanne, era de suponer que la Real Academia médica matritense dejaría traslucir en sus juntas o en sus escritos semejante interés por aquella novedad. Quizá, en los años inmediatos a 1a formación en Francia en 1772 de una institución destinada a la salvación de ahogados y asfixiados, unos académicos debatieron el tema en cierta ocasión, pero no lo sabremos, ya que se extraviaron todas las actas de las juntas celebradas desde 16 de marzo de 1752 hasta 5 de octubre de 1791 que se hallaban en el libro $2^{\circ}$ de acuerdos, pérdida deplorable que consignó por escrito el nuevo secretario al abrir el libro $3^{\circ}$. Y además, lo dudamos. Poquísima cosecha se recoge del examen metódico de las carpetas del archivo, y el nombre de Pia o de Gardanne no aparece ni una vez a lo largo de los años transcurridos. Los únicos datos que se refieren algo al asunto o a personajes de nuestro estudio, son los siguientes:

Carpeta 6 (clasificada sólo en parte). Disertación sobre la irritabilidad en ahogados y asfixiados (s. n. ni fecha, pero antes de 1790).

Junta de 10 de enero de 1793. Lectura de la memoria sobre los riegos de agua en la insolación de Pedro Domenech y Amaya, 16 folios en $4^{\circ}$. Su autor admitido en la clase de correspondiente.

Junta de 16 de mayo de 1793. Comunicación de R.O. de 24 de abril, sobre que se remita la memoria de Domenech y Amaya con el informe correspondiente. El Vice Presidente y Franseri designados para la censura.

En la junta de 20 de junio, se acordó que el Vice Secretario avise al Ministro de Estado que la Academia consideraba dicha memoria digna de luz pública.

Junta de 16 de abril de 1795. El Vice Presidente y García Fernández propusieron a D. Josef Ignacio Samponts para asociado natural. Fue admitido en la junta de 23 de abril de $1795^{59}$.

59 Este propagador de la máquina fumigatoria de Gardanne falleció el 10 de febrero de 1797. 
Junta de 11 de junio de 1795: Iberti60 leyó su memoria acerca de los efectos del alkali volátil sobre las sustancias animales. Fue aprobada para unirla a las memorias de la Academia.

Carpeta 9. Oficio de Cevallos, Protector de la Academia desde junio de 1803, pasando a manos del Secretario de R.O. de 25 de septiembre el manuscrito italiano titulado Circular de la Regencia del Archiducado de Austria sobre la formaciôn de un instituto para rebocar a los asfíticos a los que padecen muertes aparentes (Viena, 19 de junio de 1803), «para que la Academia haga el uso que estime oportuno». El texto de la circular se encuentra en la carpeta10.

Junta de 6 de octubre de 1803 : Martínez de San Martín se encargó de la traducción de la circular y leyó su traducción en la junta de 13 de octubre de 1803.

Carpeta 15. Disertación de Sage sobre el alkali volátil fluor. Traducción hecha por Casimiro Ortega. El autor dice que los españoles han sido los primeros traductores de sus experiencias.

Junta de 24 de abril de 1806 : El Sr Juez de Imprentas remite a censura de la Academia una noticia extractada de las obras de Portal, hecha por Tomás García Suelto. En la junta de 19 de junio, el Secretario presentó, en ausencia del traductor, ante nueve Académicos reunidos, los extractos del «célebre Portal» sobre los medios de socorrer a los ahogados...

Junta de 25 de septiembre de 1806: García Suelto regaló para la biblioteca el primer volumen de la Anatomía médica del Dr Portal, traducida al castellano por el mismo.

Más interesante, aunque muy escueta y lacónica, es la reseña atribuida a la palabra «Ahogados» en el tomo $1^{\circ}$ del Diccionario de Ballano que aconseja: «El introducir humo de tabaco por el ano, es otra de las diligencias que se deben practicar, para lo qual es preciso valerse de la máquina fumigatoria bastante conocida».

Raquítica cosecha en verdad desde 1791 hasta más allá de 1815, que demuestra claramente que la Academia de Medicina matritense sólo se interesó por Sage y Portal y que la sugerencia de su Protector de estudiar la conveniencia de crear en España un establecimiento en favor de los muertos aparentes, semejante a los numerosos que existían en Europa desde 1768, no tuvo la menor aceptación ni se debatió en ninguna junta. Si las cajas fumigatorias circularon en España, no fue por recomendación de la Academia, ni por decisión del gobierno. Su adquisición sólo se debió a iniciativas particulares.

Desde ese final del siglo XVIII y de sus incertidumbres ante la muerte real o aparente, parecerán hoy en día, con los adelantos prodigiosos de la medicina, algo irrisorios tantos esfuerzos descomunales para combatir el juicio errado de tener por difuntos a los que sólo estaban sincopizados y hacer de aquellos muertos aparentes, «revinientes» o «redivivos», tras larguísimas horas de cuidados ininterrumpidos. Hoy, parecerán definitivamente superadas las dudas que movieron a compasión a los médicos europeos del XVIII. Pero entonces, ¿qué opinar de este recorte del periódico Le Progrès de Lyon, aparecido el 19 de septiembre de 1981, que lleva por título: «En la Alemania federal, cinco personas de cien mil están enterradas vivas» El médico legista de Tubingen, el Profesor Hans Joachim Mallach, acaba de declarar que en la

\footnotetext{
60 Académico numerario, médico de cámara de S.M. y Primer Catedrático de Medicina Práctica de
} Madrid, Iberti murió poco después en 1796. 
Alemania federal, de cien mil fallecimientos oficialmente declarados por un médico, cinco no son más que muertes aparentes, muertos vivos. Esta cifra, prosigue el Profesor Mallach, lleva a constatar que, cada año, 35 personas están enterradas vivas... Esta información trágica, a pesar de haber sido explotada por la prensa sensacionalista, como por ejemplo el Bild Zeitung con su tirada de cinco millones de ejemplares, no deja, comenta el redactor del artículo, de fundarse en bases científicas precisas. Durante el congreso de medicina de Kiel en que se hicieron estas revelaciones, otro médico, e1 Profesor Wolfgang Eisenmenger de Munique, explicó cómo se producían aquellas terribles equivocaciones y distinguió tres categorías de accidentes susceptibles de provocar la muerte, pero también, en casos determinados, de no provocar más que una muerte aparente (intoxicaciones, congestiones repentinas debidas a1 frío, hidrocuciones con inhibición total de los centros nerviosos ...) Y para ilustrar el tema del congreso, el responsable de la Cruz Roja de Baviera, el Dr. Ludwig Tieber, relató el caso de una mujer de 50 años que en la ciudad de Oberammergau, se quedó inanimada en una bañera de agua fría. El médico llamado a su cabecera juzgó que presentaba todos los síntomas de muerte por hidrocución, firmó la partida de defunción y la licencia de inhumación. Cuando dos días más tarde, procedían los empleados de las pompas fúnebres al último aseo del supuesto cadáver, uno de ellos, estupefacto, reparó en un leve parpadeo... Unos socorros bastaron para que la mujer volviese a plena vida ${ }^{61}$.

Para concluir esta exposición con otra nota también sorprendente y estrechamente relacionada con el tema de los auxilios dispensados a los ahogados, citaré en el periódico Le Quotidien de Paris de 1977 o 1978, el breve relato siguiente: «Michèle, 3 ans, sauvée après 14 heures d'efforts». En pocas líneas, se cuenta que un 9 de febrero, la niña cayó en una piscina. Cuando más tarde su tía la rescató, estaba clínicamente muerta. Su corazón había dejado de latir y sus pulmones ya no funcionaban. Transportada a un hospital, un sacerdote le administró la extrema unción. A pesar de la evidencia del fallecimiento, una pareja de médicos internos se empeñó en tentar lo imposible y tras 14 horas de esfuerzos ininterrumpidos, su labor fue recompensada: paulatinamente, las funciones vitales se pusieron en marcha y la niña recobró la vida. El Dr. Sam Giammona del Hospital de Niños de San Francisco que refirió el caso, declaró que en los Anales de la Medicina.1a niña Michèle McQuiston era el tercer caso conocido de supervivencia, tras un paro cardíaco...

¿Será que los Anales de la Medicina ignoran los innumerables e irrebatibles casos de reviviscencia que se consiguieron en el siglo XVIII, en Holanda, Inglaterra, Francia, Suiza, Italia, Alemania, Austria, España, Portugal ...merced a la humanidad y a la

61 Igualmente, se puede leer en el Mateh de 21 de septiembre de 1979 ( $\mathrm{n}^{\circ}$ 1582) una entrevista concedida al Dr. Péron Autret, autor de un libro reciente titulado «Los enterrados vivos». El médico ilustrando su propósito con varios casos concretos, declara que el riesgo sigue existiendo hoy día y lo valora en un 4\%. Según él, no se hacen todas las pruebas científicas necesarias entes de decretar la muerte verdadera de una persona y los plazos legales para la inhumación son insuficientes. 
abnegación sin par de miles y miles de médicos y socorristas? A1 iniciar este estudio, decía que el siglo XVIII no parecía muy lejano. Pero sí, con esta reflexión del Dr. Sam Giammona, lo hemos rechazado muy lejos de nosotros. Claro está que lo hemos olvidado del todo, hasta cuando una de sus aspiraciones más encomiables fue traer al hombre la felicidad por la filantropía. 